\title{
Vaccination in England: a review of why business as usual is not enough to maintain coverage
}

Tim Crocker-Buque* (1) and Sandra Mounier-Jack

\begin{abstract}
Background: The vaccine system in England underwent radical changes in 2013 following the implementation of the Health and Social Care Act. There have since been multi-year decreases in coverage of many vaccines. Healthcare professionals have reported finding the new system fragmented and challenging. This study aims to produce a logic model of the new system and evaluate the available evidence for interventions to improve coverage.

Methods: We undertook qualitative document analysis to develop the logic model using process evaluation methods. We performed a systematic review by searching 12 databases with a broad search strategy to identify interventions studied in England conducted between 2006 and 2016 and evaluated their effectiveness. We then compared the evidence base to the logic model.

Results: We analysed 83 documents and developed a logic model describing the core inputs, processes, activities, outputs, outcomes and impacts of the new vaccination system alongside the programmatic assumptions for each stage. Of 9,615 unique articles, we screened 624 abstracts, 45 full-text articles, and included 16 studies: 8 randomised controlled trials and 8 quasi-experimental studies. Four studies suggest that modifications to the contracting and incentive systems can increase coverage, but changes to other programme inputs (e.g. human or capital resources) were not evaluated. Four multi-component intervention studies modified activities and outputs from within a GP practice to increase coverage, but were part of campaigns or projects. Thus, many potentially modifiable factors relating to routine programme implementation remain unexplored. Reminder/recall systems are under-studied in England; incentive payments to adolescents may be effective; and only two studies evaluated carer information.

Conclusions: The evidence base for interventions to increase immunisation coverage in the new system in England are limited by a small number of studies and by significant risk of bias. Several areas important to primary care remain unexplored as targets for interventions, especially modification to organisational management.
\end{abstract}

Keywords: Vaccination, Immunisation, Primary care, Organisational management, Systematic review

\section{Background}

The system for delivering vaccinations to the population in England underwent a radical change in 2013 following the implementation of the Health and Social Care Act 2012 [1]. Although General Practitioners (GPs) in primary care clinics (GP practices) retain responsibility for the delivery of vaccinations to their population, the organisations involved in agreeing the schedule of recommended vaccines, commissioning and funding of the service,

* Correspondence: timothy.crocker-buque@lshtm.ac.uk

Faculty of Public Health and Policy, London School of Hygiene and Tropical Medicine, 15-17 Tavistock Place, London WC1H9SH, UK and the collection and analysis of epidemiological data, changed radically with the formation of new organisations including NHS England (NHSE), Public Health England (PHE) and NHS Digital (NHSD). A tripartite group of organisations with responsibility for vaccination in England (the Department of Health (DH), PHE and NHSE) then went about developing and implementing a new operational model. This reorganisation was extremely disruptive to the delivery of the vaccination programme and the outcome has been described as "fractured" resulting in a "complex mesh", causing difficulties for professionals delivering vaccinations on the ground [2]. At the same time the schedule of routine

(c) The Author(s). 2018 Open Access This article is distributed under the terms of the Creative Commons Attribution 4.0 International License (http://creativecommons.org/licenses/by/4.0/), which permits unrestricted use, distribution, and reproduction in any medium, provided you give appropriate credit to the original author(s) and the source, provide a link to the Creative Commons license, and indicate if changes were made. The Creative Commons Public Domain Dedication waiver (http://creativecommons.org/publicdomain/zero/1.0/) applies to the data made available in this article, unless otherwise stated. 
vaccines has continued to increase in size and complexity, now with 16 childhood vaccinations given to 6 age groups; 2 or 3 vaccines for adolescents; and 3 in older adults [3].

These factors may have influenced vaccine coverage. Although coverage for core childhood vaccinations remains high overall, downward trends have emerged since 2012 for several important vaccines, for example, measles, mumps and rubella vaccine (MMR) at 2 years decreased for the $3^{\text {rd }}$ consecutive year and currently stands at $91.6 \%$, below the $95 \%$ target set by the World Health Organisation [4]. This is particularly concerning given the 5 recent outbreaks in England and the measles epidemic currently affecting many other European countries [5, 6]. Similarly, coverage of pentavalent vaccine (containing diphtheria, tetanus, pertussis, polio and haemophilus inflenzae b) by 12 months has decreased each year since 2012 [4]. Coverage is also not evenly distributed, with specific geographic areas having significantly lower coverage than the England average. This is particularly important in London where the lowest coverage is found for all childhood vaccines [4]. Similar trends are found in vaccine coverage in adults. For example, shingles vaccine was introduced into the schedule in 2015 for people aged over 70 years, with a catch-up campaign for people over 78 . However, this year coverage is only $34.6 \%$ and $34.8 \%$ in each of these age groups respectively, which is $5.5 \%$ and $5.3 \%$ lower than the preceding year and shows a downward trend [7]. While demographic and socio-economic factors are well known to impact vaccine coverage, resulting in significant inequities between population groups, $[4,8-19]$ the contribution of health service organisation is unknown. GP Practices are independent contractors to the NHS and so organisational management data relating to their operating structure and function are not readily available. Although GP Practices are critical for successful delivery of the programme, within the post-2013 system there is also much less advice and support available from both NHSE and PHE, compared to the previous model, leaving practices isolated [2].

Many systematic reviews have been conducted evaluating interventions to improve coverage in high income countries: in specific population groups, including children, [20], adolescents, [21] people over 60, [22], children with high-risk conditions, [23] and looked-after children; [24] in specific scenarios, including reducing hesitancy, [25] missed opportunities, [26] and inequalities; [27] and evaluating specific types of interventions, including reminder/ recall systems, $[28,29]$ mobile phone messages, [30] education, [31] eHealth, [32] primary care service delivery, [33] health worker reminders, [34] and financial incentives for doctors, [35] and patients [36]. However, there has been no consideration of how this evidence has been applied in the England context, nor whether the outcomes of any trials match those in the broader evidence. Therefore, the aims of this study are to i) develop and describe a logic model for the implementation of the vaccination programme in England; ii) undertake a systematic review of interventions that have modified vaccination programme delivery in England; iii) compare the evidence in England to existing evidence from high-income countries; and iv) evaluate how this evidence relates to critical components of the logic model to identify potential targets for improvement to increase coverage

\section{Methods}

\section{Document analysis and logic model}

The purpose of developing the logic model is to accurately describe the components of the system for delivering the routine vaccination programme, including the underlying programmatic assumptions. To develop the model, we undertook a systematic analysis of documents published by organisations involved in designing and delivering the routine vaccination programme in England. We searched the websites of the following organisations for relevant documents: UK Government, including Department of Health and Public Health England (www.gov.uk), NHS England (www.england.nhs.uk), NHS Digital (www.digital. nhs.uk), British Medical Association (www.bma.org.uk), Royal College of Nursing (www.rcn.org.uk), and conducted a general search through Google (www.google.co.uk). Search terms consisted of "vaccination" and "immunisation" and spelling variants (Fig. 1). The focus was on documents relevant to the system since the implementation of the 2012 Health and Social Care Act, i.e. 2013-2017. We uploaded the included documents into NVIVO (v11) for qualitative analysis using document analysis methods [37].

The content of each included document was coded using deductive codes derived from the categories in logic model development (inputs, processes, activities, outputs, outcomes and impact). These were then synthesised and used to form a logic model with accompanying programmatic assumptions using the principles of process evaluation [38].

\section{Systematic review}

We designed the systematic review to identify interventions that have been conducted within vaccine delivery programme in England. This has been reported in line with the PRISMA Guidelines for Systematic Reviews [39].

\section{Search strategy}

We searched Medline, ASSIA, Campbell Collaboration, Cochrane Database of Systematic Reviews, Embase, EPPI Centre, Psych Info, Web of Science, SCOPUS, Social Policy and Practice, Health Systems Evidence and Health Management Information Consortium using the search strategy shown in Additional file 1. 


\begin{tabular}{|c|c|c|c|}
\hline $\begin{array}{l}\text { Search target: www.gov.uk } \\
2,478 \text { search hits, of which } 846 \\
\text { were reviewed for relevance } \\
\text { (relevance decreased through } \\
\text { search hits) } \\
143 \text { documents identified and } \\
\text { reviewed. }\end{array}$ & $\begin{array}{l}\text { Search target: } \\
\text { www.england.nhs.uk/publication/ } \\
722 \text { search hits reviewed. } 67 \\
\text { documents identified and reviewed } \\
\text { plus } 35 \text { documents direct from } \\
\text { Public Health Commissioning } \\
\text { (www.england.nhs.uk/commissioni } \\
\text { ng/pub-hlth-res/) } \\
\text { www.digital.nhs.uk: } 67 \text { search hits } \\
\text { reviewed, } 13 \text { documents identified. }\end{array}$ & $\begin{array}{l}\text { Search target: } \\
\text { www.nhseployers.org: } 224 \text { search } \\
\text { hits reviewed, } 13 \text { documents } \\
\text { identified and reviewed. } \\
\text { www.bma.org.uk: } 258 \text { search hits } \\
\text { reviewed, } 6 \text { documents identified } \\
\text { and reviewed. } \\
\text { www.rcn.org.uk: } 11 \text { search hits } \\
\text { reviewed, } 0 \text { documents identified. }\end{array}$ & $\begin{array}{l}\text { Search target: www.google.co.uk } \\
\text { Search terms: (vaccine OR } \\
\text { vaccination OR immunise OR } \\
\text { immunisation) AND (England OR UK } \\
\text { or NHS) filtered 2012-2017, } \\
\text { resulting in } 102 \text { pages, of which } 26 \\
\text { documents were reviewed for } \\
\text { relevance. }\end{array}$ \\
\hline $\begin{array}{l}\text { Included: } \\
\text { JCVI Meeting Notes (16) } \\
\text { Vaccine Updates (15) } \\
\text { Non-flu policy reports and guidance } \\
\text { (PHE: 7, DH: 5) } \\
\text { All chapters of 'The Green Book' } \\
\text { national vaccination guidance. }\end{array}$ & $\begin{array}{l}\text { Included: } \\
\text { Vaccination related service } \\
\text { specifications (20) } \\
\text { Vaccine policy reports or service } \\
\text { guidance (9) } \\
\text { NHS Digital Reports (2) }\end{array}$ & $\begin{array}{l}\text { Included: } \\
\text { NHS Employers: contract reports } \\
\text { (2) } \\
\text { BMA: } 1 \text { policy report and } 1 \\
\text { guidance document. }\end{array}$ & $\begin{array}{l}\text { Included: } \\
\text { Health Technology Assessment (1), } \\
\text { academic reports (2), nursing } \\
\text { report (1), independent panel } \\
\text { report (1) }\end{array}$ \\
\hline
\end{tabular}

Fig. 1 grey literature search strategy for document analysis

\section{Inclusion and exclusion criteria}

Studies with the following characteristics were included:

- Population: any in England

- Dates: published between 1996 and 2016

- Study design: Randomised Controlled Trial (RCT), quasi-experimental (including time-series and before-and-after studies) and ecological studies.

- Interventions: any designed to increase vaccine uptake or coverage, including any associated economic analyses.

Due to the complex and diffuse nature of the immunisation delivery system in England, we allowed for a wide range of study designs to be included. Additionally, we reviewed the references for other systematic reviews on similar topics that could have contained studies that fitted our inclusion criteria.

\section{Study selection process}

One reviewer screened articles by title and manually de-duplicated records (TCB). Two reviewers screened potentially relevant abstracts independently (TCB, SMJ). Any disagreement was resolved by discussion, based on the inclusion criteria. Both reviewers agreed the final inclusions.

\section{Data extraction and assessment of bias}

We extracted the following data from each included study for comparison: design, dates, population, intervention, vaccine(s), comparison, sampling method, allocation method, randomisation method, blinding, outcome measure and effect measure.

For RCTs, risk of bias was evaluated using the Cochrane Collaboration tool, with aspects of each study relating to selection bias, performance bias, detection bias, attrition bias, reporting bias and other bias extracted [40]. The Cochrane Collaboration tool is not specific to non-randomised study designs, and so, for quasiexperimental study designs, risk of bias was evaluated with the relevant Study Quality Assessment Tool published by the USA National Heart, Lung and Blood Institute, which are available for a variety of non-randomised study designs [41]. Both reviewers undertook assessment independently then compared outcomes and resolved differences by discussion.

\section{Results}

Logic model

For the grey literature search 2,230 search hits generated 303 documents that were reviewed for inclusion (Fig. 1). The components of the logic model were identified from 83 documents from the following sources:

- NHS England (NHSE): service specifications $(n=20)$ and policy or guidance reports $(n=9)$

- Public Health England (PHE): Vaccine Updates published in 2017 ( $n=15)$, other policy or guidance reports $(n=7)$, and The Green Book.

- Department of Health (DH): policy reports $(n=5)$, Joint Committee on Vaccines and Immunisation (JCVI) meeting notes for 2013-2017 $(n=16)$

- NHS Employers: contract reports $(n=2)$ 
- NHS Digital (NHSD): reports $(n=2)$

- British Medical Association (BMA): reports or guidance $(n=2)$

- Other relevant academic or grey literature $(n=5)$

\section{Purpose}

The purpose of the routine vaccination programme is described in the NHS Public Health Functions Agreement 2017-18 Core Service Specification National Immunisation Programme document, published by PHE and NHSE, as "to protect the population from vaccine preventable diseases and reduce the associated morbidity and mortality." [42]. For the purposes of developing this logic model the intervention was defined as: the immunisation of individuals with pre-specified characteristics (e.g. age, co-morbidity, pregnancy) with immunological agents delivered by vaccination to prevent morbidity and mortality from vaccine preventable diseases (VPD) and reduce microbial spread within the population. The focus of this paper is the delivery of vaccinations through primary care facilities, so this is considered as the core activity.

\section{Logic model and assumptions}

The logic model derived from the document analysis is presented in Fig. 2. Alongside GP Practices, there are 7 core organisations identified within the system: Department of Health (DH), the government department responsible for health; Public Health England (PHE), an executive agency of the DH with responsibility for vaccination; the Joint Committee on Vaccines and Immunisations (JCVI), an advisory group of independent experts for which PHE acts as secretariat; NHS England (NHSE), an executive non-departmental part of the $\mathrm{DH}$ responsible for commissioning (buying) vaccination services; NHS Digital (NHSD), which provides data systems and published some coverage statistics; the British Medical Association (BMA), the trade union and professional association of doctors in the UK, and the General Practitioners' Committee (GPC), which is responsible for negotiating commissioning arrangements; the Medicines and Healthcare Products Regulatory Agency (MHRA), an executive agency of the DH with responsibility for safety of vaccines.

\section{Inputs}

We identified five key inputs for the vaccine programme: i) funding, ii) human resources, iii) primary care facilities, iv) data and v) vaccines. Funding is raised by general taxation and allocated by the Secretary of State from DH to NHSE via the Section 7A Agreement for use in commissioning public health services, including immunisation. The primary

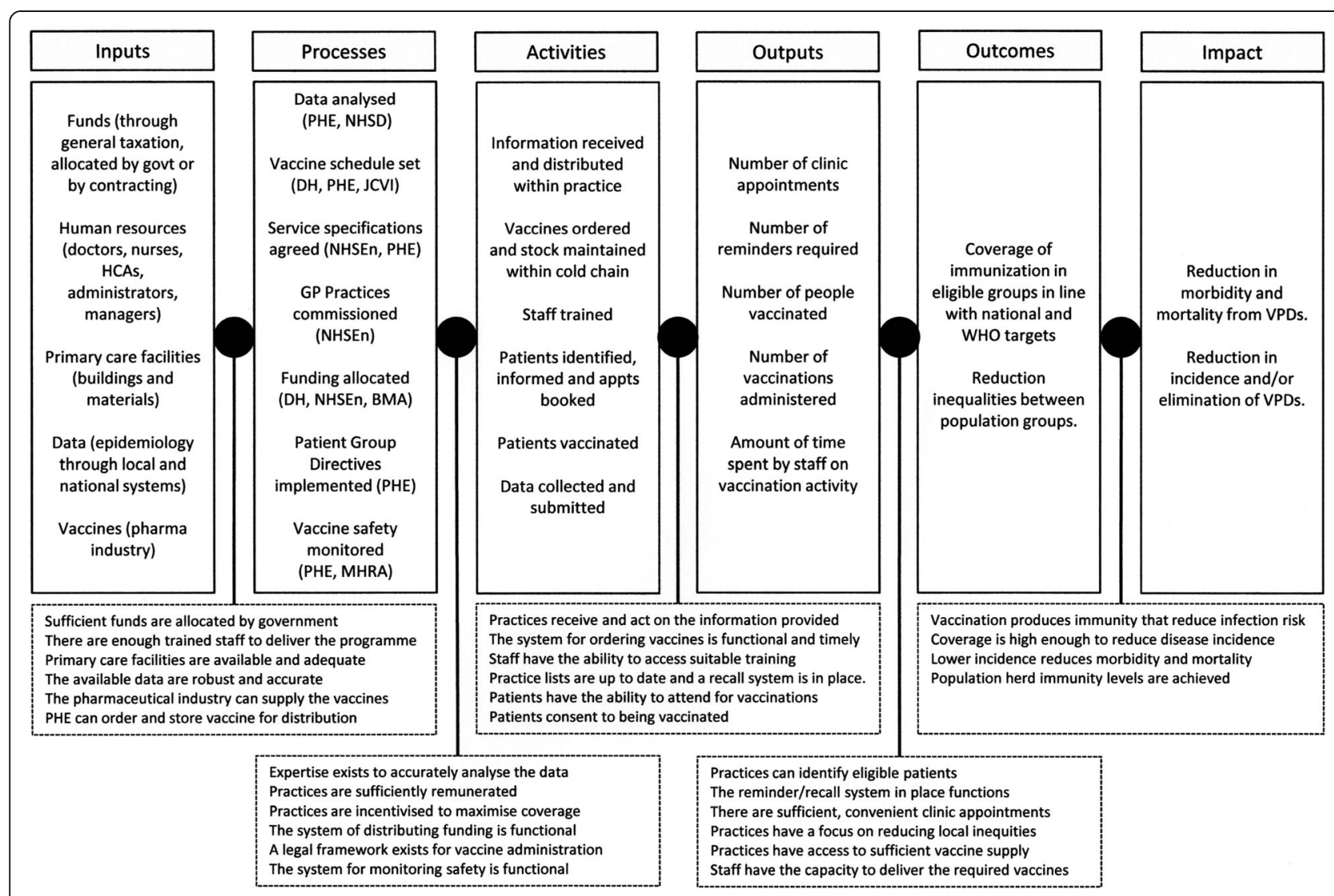

Fig. 2 Logic model of the process of delivering the routine vaccine schedule in England with underlying assumptions 
assumption is that this funding is sufficient to provide the programme. Vaccines are not included in this funding and are instead bought directly by DH and stored at PHE. Human resources are considered primarily at the GP Practice level, with assumptions that there are sufficient staff locally who have access to all the required facilities and resources. The expectations of the core and specific requirements for immunisation service are set out in NHSE's Core Service Specification for the National Immunisation Programme, and each of the individual service specifications for each vaccine.

\section{Processes}

Seven core processes were described in the documents: i) data collection analysis, ii) setting the vaccine schedule, iii) producing the service specifications, iv) commissioning arrangements through contracting, v) allocation of funding, vi) production of patient group directives, and vii) monitoring vaccine safety.

Data are collected through two parallel systems: the Child Health Information System (CHIS); and ImmForm [43]. There are multiple, regional CHIS providers in England. It is a historical system that is commissioned independently by NHSE and collects data on core childhood immunisations [44]. ImmForm is a data collection, analysis and ordering platform commissioned by $\mathrm{DH}$ and PHE that mainly contains data on newer vaccines. Data analysis is primarily undertaken by PHE, with some stored and published by NHSD.

The recommended vaccine schedule is set by $\mathrm{DH}$, following recommendations from the JCVI with specialist input from PHE. NHSE is tasked with commissioning vaccination services from GP Practices in England as per the Section 7A Agreement and does this through the immunisation service specifications and the more general contracting arrangements, such as the General Medical Services (GMS) and Personal Medical Services (PMS) contracts. The contents of these are negotiated annually with the GPC. PHE staff embedded within NHS England's regional area teams provide oversight of the implementation of the programme. Nurses and Healthcare Assistants (HCAs) are legally enabled to vaccinate specific population groups without an individual prescription using a Patient Group Directive (PGD). Safety is monitored both by PHE and the MHRA through individual reporting using the Yellow Card notification system, [45] and population level studies.

\section{Activities at GP Practices}

GP Practices are expected to provide a minimum set of activities with the aim of "offering immunisation to 100\% of eligible individuals in accordance with... guidance from DH, NHSE and PHE" [42]. These are set out in the service specifications and The Green Book, [46] which is the handbook of guidance relating to immunisation, published and updated by DH and PHE, with advice from JCVI. Broadly, the activities include: contacting and vaccinating eligible patients; keeping accurate records; training staff annually; providing an accessible service; providing information to patients; collecting and submitting data; involving users in service design; considering vulnerable and under-immunised groups; managing vaccine stock; and maintaining the cold chain. The key assumptions are that practices are sufficiently resourced and incentivised to undertake these activities.

\section{Outputs}

The outputs expected from the GP Practice are not clearly defined. The focus in the specifications is on providing data on the number of vaccinations administered to the eligible population, although there is also some consideration of availability and uptake of appointments and the use of a reminder and recall system. There is no consideration of staff time, capacity or cost. The main assumptions are that: practices have accurate lists and make sufficient appointments available; the reminder/recall system is in place and functional; the system for ordering vaccine stock and maintaining the cold chain is in place; and that patients attend and consent to vaccination.

\section{Outcomes}

The outcomes are more clearly defined, with coverage of immunisation within eligible populations is a core focus of all the documents. National level coverage expectations are described in the Core Service Specification, through which DH holds NHSE to account, which are based on coverage achieved in previous years or global recommendations from the WHO. As a result, coverage levels are reported by PHE and considered by JCVI. There is also a statutory requirement to reduce inequalities between groups, specified as people with protected characteristics as defined in the Equality Act 2010 [47]. The assumptions here are that the systems and activities undertaken by the GP Practice's work sufficiently well to vaccinate high levels of the local population and that these local data aggregate to these thresholds nationally.

\section{Impacts}

The purpose of the programme as stated in the Core Service Specification "is to enable [NHSE] to commission national immunisation services to a standard that will continue to minimise the infections and outbreaks caused by vaccine preventable diseases... and... to protect the population from vaccine preventable diseases and reduce the associated morbidity and mortality." This aim is reflected as a disease specific aim in each of the individual service specifications. Much of the focus on vaccination policy at the JCVI is on reduction of circulating disease 
prevalence. Disease elimination is also a stated aim of the programme, for example, the Section 7A agreement contains the WHO European regional target to eliminate measles and rubella infections by 2020 . The assumptions here are primarily that the vaccinations recommended in the schedule produce sufficient immunity to reduce disease incidence; and that coverage is high enough to reduce pathogen circulation to reduce outbreaks and move towards elimination.

\section{Systematic review}

The PRISMA Flow Chart of study selection and inclusion is presented in Fig. 3. Of 9,615 unique articles, 624 abstracts were screened, leading to 43 full text articles being reviewed. A further 2 studies were identified from the references of 8 other review articles [27, 33, 35, 36, 48-51].

In total 16 experimental studies were included: 8 RCTs (Table 1) and 8 quasi-experimental studies (Table 2). Four studies considered seasonal influenza, [52-55] with 2 more looking at influenza and pneumococcal vaccines together; [56, 57] 5 considered measles, mumps and rubella (MMR); [58-62] 3 the whole childhood schedule; [63-65] 1 each considered pneumococcal vaccines alone and human papillomavirus (HPV) vaccines; $[66,67]$ and 3 looked at the effect of the Quality Outcomes Framework (QOF), an incentive scheme, focusing on influenza coverage in specific risk groups $[8,68,69]$.

Due to heterogeneity in study populations and intervention types meta-analysis was not possible, except in one case where it had already been performed elsewhere in the literature.

\section{Randomised controlled trial interventions}

Four studies examined reminder/recall interventions in increasing uptake of seasonal influenza vaccination in adults [52-55]. Two of these combined reminders to eligible patients with a home visit component, compared to reminders alone $[52,54]$. One study had a high risk of performance and attrition bias and the other had a low risk of bias but was under-powered (90 subjects). In a previous systematic review and meta-analysis evaluating interventions to increase uptake of influenza vaccine in people over 60 , the pooled effect of these studies involving 710 intervention patients (who received a reminder and a home visit) and 1402 controls with 'usual care' was an odds ratio (OR) of 1.30 (95\% confidence interval (CI) $1.05-1.61, \mathrm{p}=0.01)$. However, neither evaluated the additional cost of the home visit component. Of the studies considering reminders alone, one compared a phone call from a receptionist to sending a letter and found an OR of 1.29 (CI 1.03-1.62) and the other evaluated using text message reminders at practice level, finding a nonsignificant OR 1.12 (CI 1.00-1.25) increase in uptake. Both provided evidence with low risk of bias.
Two studies used educational interventions to increase uptake of MMR vaccine. One used a teddy-bear with signposting to government information and found no difference between intervention and control groups and was at high risk of bias [58]. The other evaluated a webbased decision aid as compared to a leaflet and compared to usual practice alone and found OR 0.14 (CI 0.02-1.14) lower coverage in the leaflet group compared to usual practice (OR 0.14 (CI 0.02-1.14) ) and higher coverage in the decision aid group compared to the leaflet (OR 10.6 (CI 0.1-188.5)), but no difference between decision aid and usual practice groups [59]. However, sample size was small (220 in three groups) and confidence intervals were wide. An associated cost-effectiveness analysis found the decision aid was lower cost to deliver than usual practice $(-£ 9.20)$ and leaflets $(-£ 7.17)$, however no direct cost was assigned to the decision aid (e.g. development and maintenance costs).

One study focussed education on healthcare workers through use of an education visit to increase uptake of both influenza and pneumococcal vaccine in people aged over 65 years in specific risk groups at practice level [56]. It found mixed results with increases in coverage in some groups (e.g. OR 1.23, CI 1.13-1.34, pneumococcal uptake in patients with cardiovascular disease (CVD)) but not in others, making overall effect difficult to establish.

$\mathrm{HPV}$ vaccine is provided to adolescent females and a study at low risk of bias and a large sample (1,000 subjects), that compared the provision of a $£ 45$ voucher and text message reminders to an invitation letter alone found a significant increase in uptake of both first dose (OR 1.63, CI 1.08-2.47) and course completion (OR 2.15, CI 1.32-3.96) in the intervention group [67]. No evaluation of cost effectiveness was made.

\section{Quasi-experimental interventions}

Most of the quasi-experimental studies use routine or population level data to evaluate the effects of either specific interventions to changes to vaccination programme implementation (Table 2). All included studies focus on changes in proportion of the eligible population covered over time, or differences in coverage between groups. Two studies with low risk of bias evaluated complex, multicomponent campaigns to improve MMR uptake in a local population, although no evaluation of cost $[60,61]$. One other study evaluated offering MMR vaccine during home visits, but was at significant risk of bias [62].

Two studies evaluated complex interventions to improve influenza and/or pneumococcal coverage in adults in risk groups. One that used quality improvement methods found significant increases in coverage across a range of vaccines, [57] and the other found an increase in coverage from 6\% to $33 \%$, so from a low start to a relatively low overall coverage level [66]. Both of these had a significant risk of bias. 


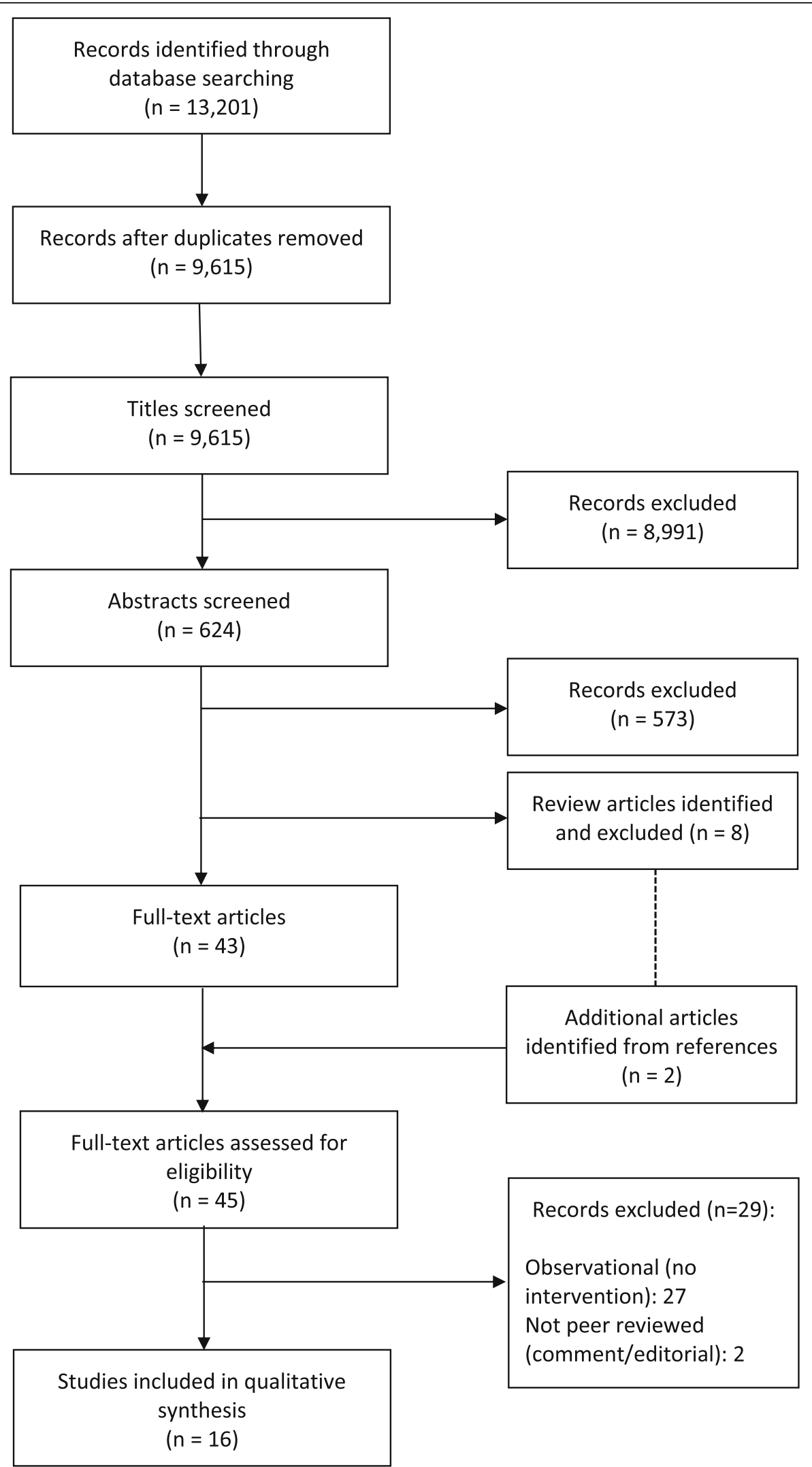

Fig. 3 PRISMA flowchart of literature selection 


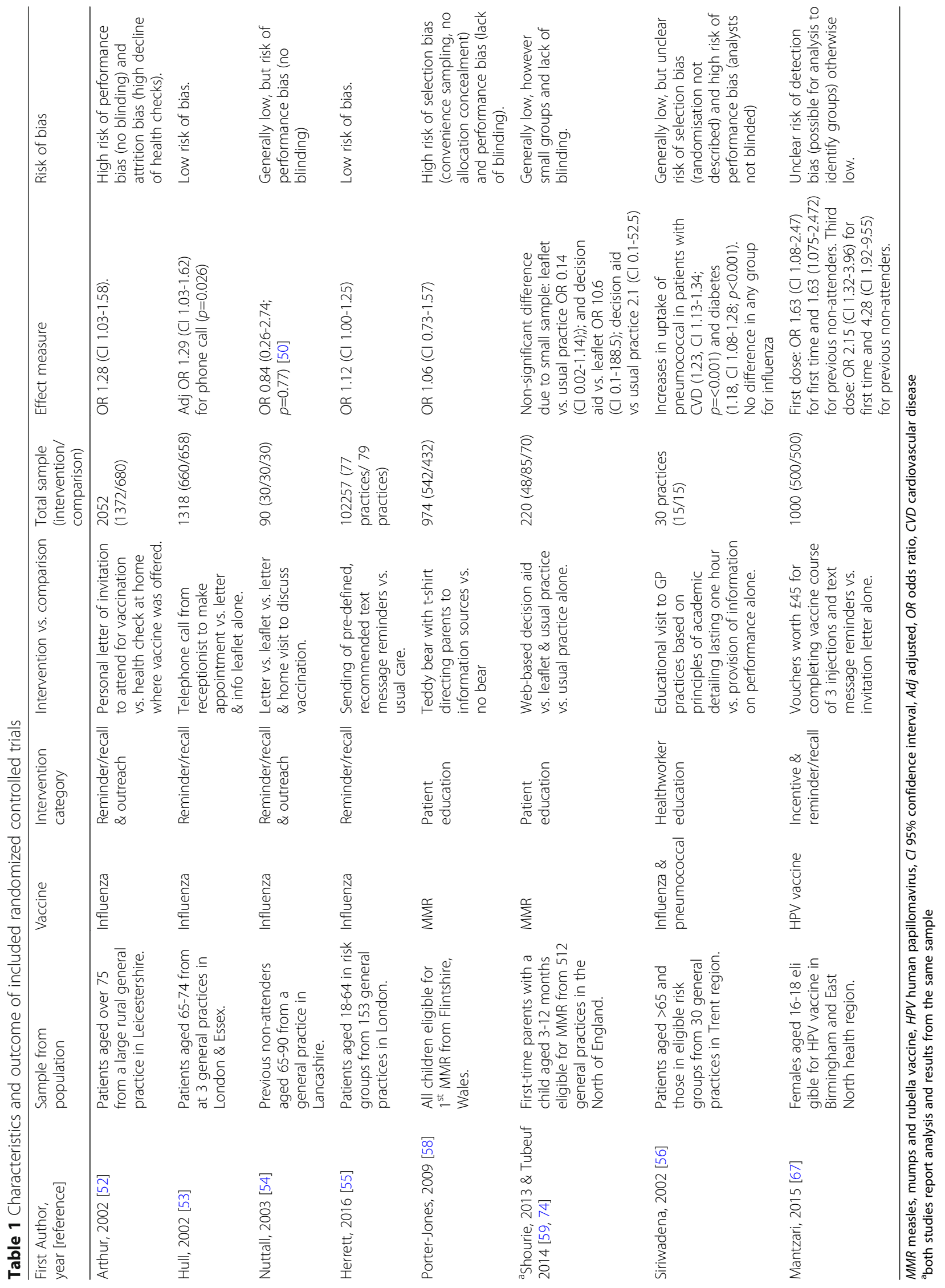




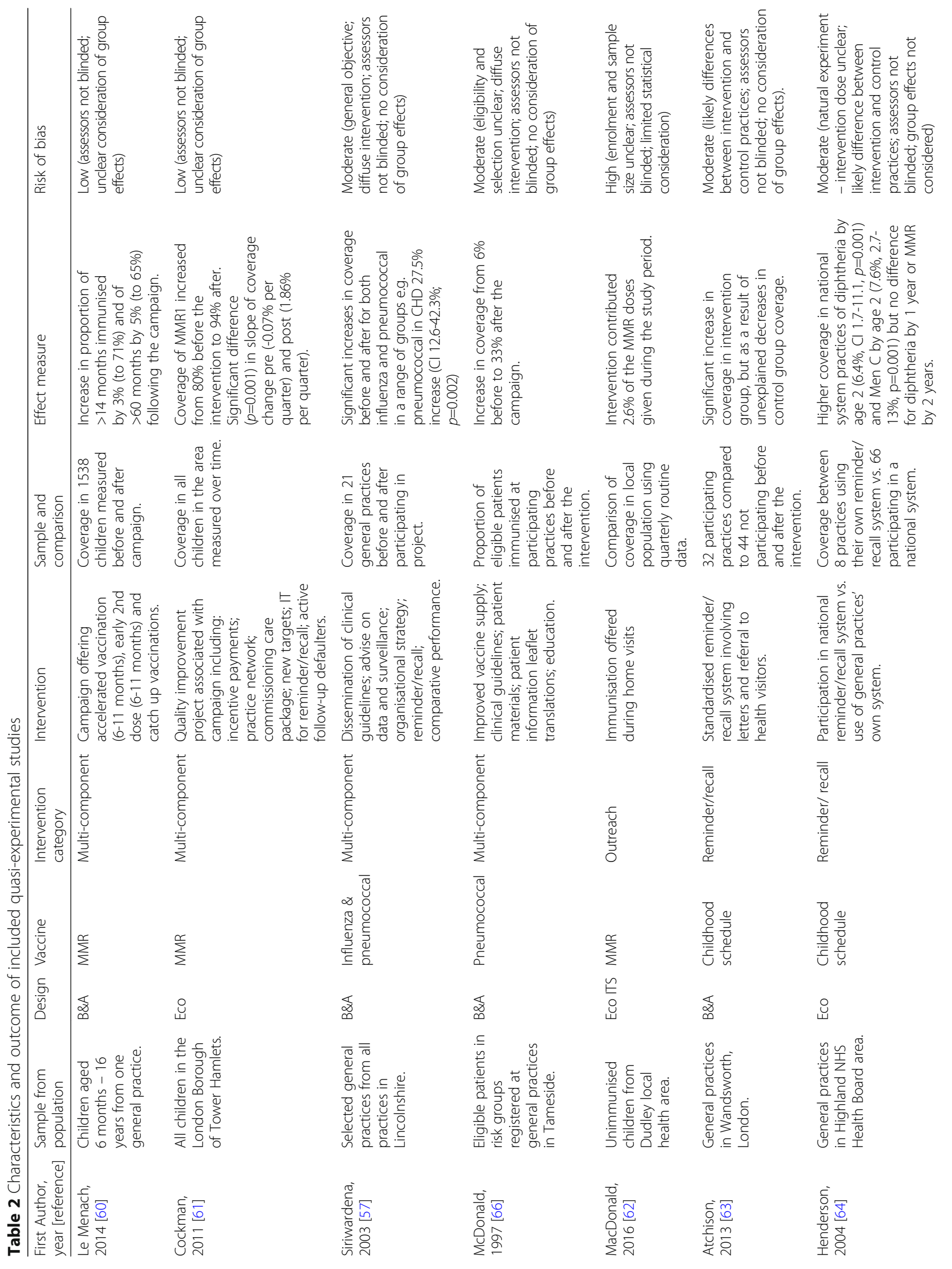




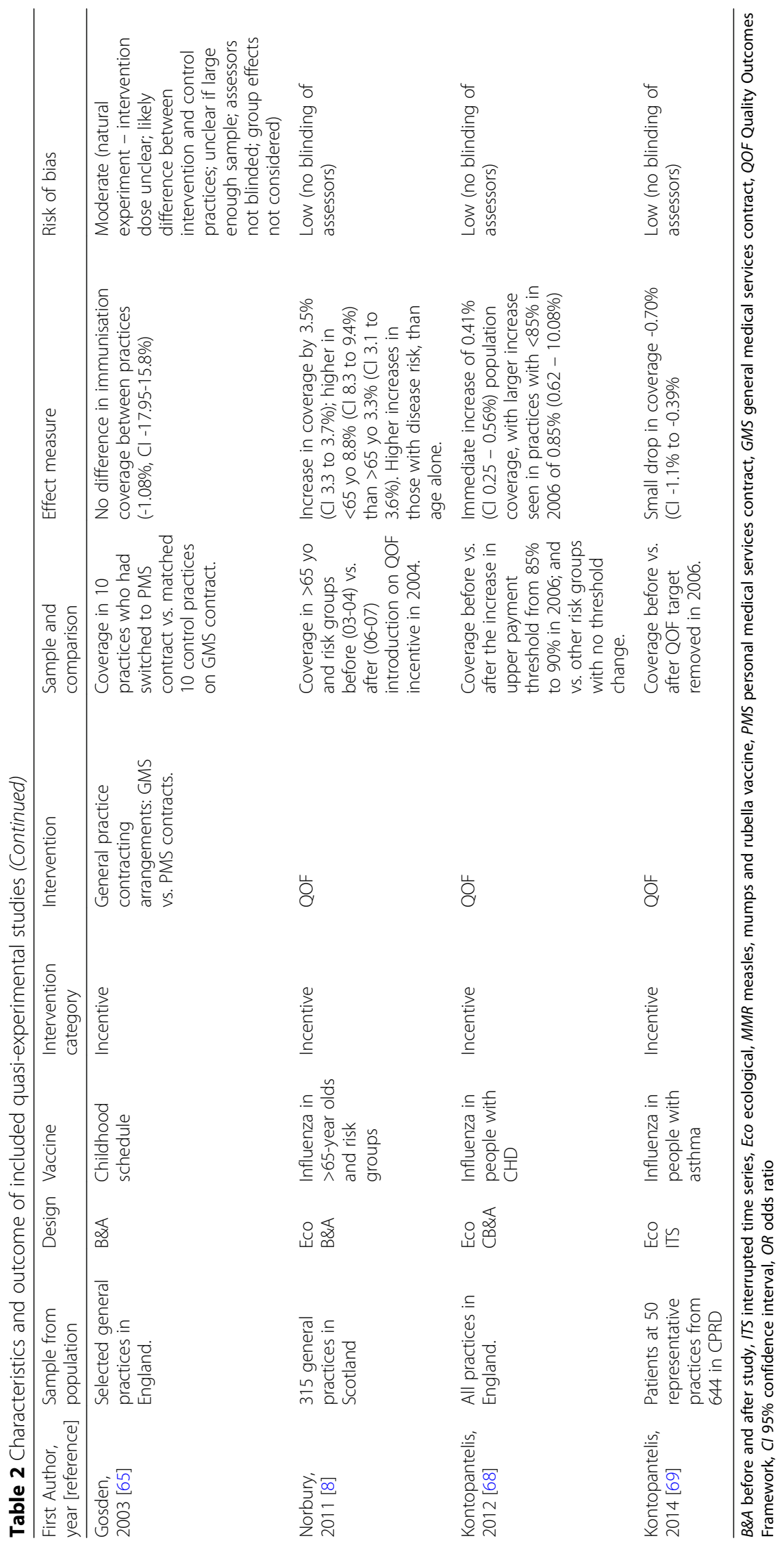


A further two studies evaluated the effectiveness of reminder/recall interventions to increase coverage of all childhood vaccines in the schedule. One implemented a standardised, complex system of reminder letters and referral to health visitors in a London borough [63]. Although a significant increase in coverage was identified, this was due to an unexplained reduction in coverage in the control group, making the results difficult to interpret. The other compared practices in Scotland using a national reminder/recall system to those using their own local systems and found higher levels in coverage in the former group, but not across all vaccines [64].

Four studies evaluated the effects of various changes to the system of contracting and payments to GP Practices in England. The first evaluated differences between practices contracted using the Personal Medical Services (PMS) contract compared to the General Medical Services (GMS) contract. The ability to switch from the standard GMS to the new PMS contract occurred in 1999 and a relatively small number of practices did so. Under the GMS contract, GPs were incentivised to increase practice list size and meet targets for providing specific services (such as immunisation) to maximise income. The PMS contract was designed to be more locally responsive with lower levels of administration and with the GPs in receipt of a salary. Overall the study found no differences between GMS and PMS practices over time, although only 10 PMS practices were included [65]. Another change to the arrangements to pay GPs was the introduction of the Quality Outcomes Framework (QOF) in 2004, a pay for performance system that incentivised GPs to meet specific quality targets [70]. This included several targets for influenza coverage in specified risk groups, including patients with asthma, diabetes and heart disease, among others. One study evaluated the effect of the introduction of these targets in Scotland and found an overall increase in coverage in 3.5\% (CI 3.3-3.7\%), but that this was far greater in incentivised populations (aged under 65 in risk groups: 8.8\%, CI 8.3-9.4\%) that in the population eligible by age alone (>65 years: $3.3 \%$, CI $3.1-3.6 \%$ ). Another study evaluated the effect of raising the threshold for payment from $85 \%$ to $90 \%$ for influenza coverage in people with cardiovascular disease in 2006 across all practices in England and found a small increase overall $(0.41 \%$, CI $0.25-0.56 \%$ ), but a larger increase seen in practices with $<85 \%$ coverage in 2006 of $0.85 \%(0.62-10.08 \%)$ [68]. In 2006 the QOF target and payment for influenza coverage in people with asthma was removed and a study was conducted in 644 practices signed up to the Clinical Practice Research Datalink (CPRD) to evaluate the overall effect, which found a small drop in coverage of $-0.70 \%$ (CI $-1.1 \%$ to $-0.39 \%$ ) [69]. Together these studies provide evidence with low risk of bias that changes to the contracting and incentive payment system can affect coverage levels, but suggest that the overall effect is likely to be small.

\section{Discussion}

In this this paper we have presented a logic model of the theoretical structure of the vaccination programme in England following the implementation of the HSCA in 2013 and identified and described the underlying assumptions that allow it to function. This will enable further work evaluating the fidelity of the implementation of this system at GP Practice level, which has not yet been studied. Through the systematic review, we have identified which aspects of the system have been modified to improve coverage, and will now compare the evidence from England to the available evidence from other high-income countries. Overall, we identified a relatively small number of experimental studies $(n=16)$. All studies used uptake or coverage to be the outcome of interest, rather than disease incidence or another impact indicator. Few of the interventions evaluated modification to routine activities and outputs within a GP Practice. Of those that did make changes at GP Practice level the modifications were associated with specific timelimited projects, $[57,63]$ or campaigns $[60,61]$. Thus, potentially modifiable factors relating to programme implementation at GP Practice level remain unexplored. Using the logic model shown in Fig. 2 we have compared this evidence to areas of programme implementation to identify un-researched areas and potential targets for future studies, and to draw lessons for policy-makers.

\section{Inputs and processes}

Four studies that modified the contracting and payment systems for GP Practices in England increased coverage. This requires modification of both the inputs (financing) and processes (contracting). A Cochrane Review originally conducted in 2000 and updated in 2009 did not find enough evidence to support the use of target payments to increase vaccine coverage, [48] and another Cochrane Review published in 2011 considering incentives for primary care physicians more broadly concluded that there is growing evidence for their use in improving quality of care, but the evidence remains limited [35]. This is likely in part due to the restriction of the evidence to RCTs, as the evidence identified here was from quasiexperimental studies using ecological data. The four studies that evaluated the impact of the introduction and changes to the QOF incentive scheme for GP Practices found that the availability of incentives is likely to increase coverage, but only by a small amount. Currently, only influenza vaccine in people with risk factors are incentivised this way and there may be merit in considering adding other vaccines to the QOF system, if coverage is low. No other incentive or financing schemes were evaluated, and this remains a significant gap in the evidence base, and there is the potential for NHSE and PHE to develop and trial other forms of incentive schemes. Additionally, other process elements, such as modifying the legal framework for 
delivering vaccines (e.g. HCAs to deliver more vaccines); or non-financial programme inputs (e.g. provision of additional facilities) have not been considered.

\section{Activities and outputs}

Most of the studied focussed on specific activities that often were developed or existed outside of the GP practice structure, including reminder/recall systems $(n=6)$, campaigns $(n=2)$, or involving elements of outreach $(n=3)$. Only four modified elements within the GP practice itself. One provided health worker education and 3 of the multi-component interventions modified a wide variety of elements of service delivery. These provide some evidence for effectiveness, although in some cases had significant risk of bias. There is wider international evidence that multi-component interventions can be effective at reducing inequalities in immunisation coverage in deprived, urban areas [27]. However, despite the chronic problems with low coverage in London, few well conducted intervention studies were identified [12]. Of those that were identified, the interventions were vaccine specific campaigns, $[60,66]$ which may not be easily reproducible, or highly diffuse interventions modifying many aspects of routine service delivery, [57, 61], which may not be relevant to other contexts. Overall, there was little consideration of the effects of interventions on core programme outputs, such as staffing levels, task shifting, information provision, service delivery models, or cost structures within GP practices. Organisational factors associated with immunisation coverage at GP Practice level have been widely studied using cross-sectional surveys. For example, a survey involving 759 practices in England evaluated factors associated with high levels of influenza coverage and found the following to have a significant independent association: identified lead staff member; written report of practice performance; personal invitation to patients; aiming for QOF targets; and using IT systems to identify patients [71]. A similar survey was conducted with 257 GP Practices in a region of England to identify factors associated with MMR coverage [72]. It found no association with practice size or number of staff (GPs or nurses); however having a strategic approach to MMR coverage and identifying clear objectives (e.g. target $>90 \%$ ) were associated with higher coverage. Modifications to the organisation of immunisation services at GP Practices should be a topic of further research and look promising as a target to increase coverage.

Robust and reliable reminder/recall systems are a core component of any vaccine programme and have very good, reproducible evidence for effectiveness [29]. Despite the risk of bias in several of the studies identified in this review, there is some evidence of effectiveness in the England context specifically, although more research would be required to identify the most cost-effective method.
Only one study considered the role of Health Visitors (HVs - community public health nurses) as part of an outreach campaign to increase MMR coverage in one area of the UK, [62] but this was compromised by very high risk of bias. One of the RCTs that had a high risk of bias found that home visits could increase coverage of influenza vaccine in older people, [73] and this may warrant repeating in areas of low coverage, with consideration of cost-effectiveness. Outreach work to improve child health, including immunisation, is usually conducted by HVs, who had formerly been based in GP Practices. In 2015, however, commissioning of $\mathrm{HV}$ services was moved to Local Authorities and most HVs left GP Practices to other locations. Currently the primary focus of a $\mathrm{HV}$ is to improve outcomes in 6 'high-impact areas', which do not include immunisation. A Health Technology Assessment review of the impact of HVs on child health outcomes, published in 2000, found good evidence for effectiveness [51]. This was not supported by the evidence identified in this study, possibly due to the nature of multiple restructures of $\mathrm{HV}$ services since 2000 .

Surprisingly, only two RCTs studied the effect of information provided to patients or carers, and both were designed to improve uptake of MMR vaccine, due to the historical controversy in this area. The provision of signposting information on a teddy-bear was not found to be an effective method, although the study was at high risk of bias, [58] and a web-based decision aid produced mixed results with small intervention groups, making firm conclusions difficult to draw [59]. None of the other intervention studies considered reducing vaccine hesitancy as an explicit aim, which is in line with the wider available evidence from other high-income countries [25]. Improving the information provided to patients would be a key area for future evaluation in the England context.

One study found that provision of a financial incentives with reminder/recall messages to adolescent females could increase uptake of HPV vaccine [67]. An extensive Health Technology Assessment evaluating incentives for parents of children eligible for vaccination, published in 2015, found limited evidence of effectiveness overall, but concluded that incentives for parents might not be acceptable, but if introduced they should be universal and not targeted [36]. If coverage in adolescent vaccines is low, then incentives could be further explored in this population.

\section{Outcomes and impact}

Evidence of effectiveness of all included studies was measured as changes in vaccine coverage levels. None considered overall impacts such as reduction in cases of VPDs, or overall morbidity and mortality. However, this is likely to be considered on a national level by PHE independent of the research evidence. Although reduction in inequalities is a key outcome of the programme, only 
one study considered the reduction in inequalities specifically [61]. Focusing vaccine campaigns or outreach interventions in areas of higher disease incidence or outbreaks may enhance the effectiveness of such programmes and provide useful evidence if evaluated.

\section{Lessons for policy}

When compared to the logic model, we identified several areas where interventions are available to support modifications to the existing system to improve coverage. These include: multi-component interventions that improve service quality in geographic areas of low coverage; incentive payments to adolescents; effective reminder/recall systems; potential use of outreach programmes; and possible modifications to contracting and incentive payments. There are also several areas of programme implementation that have not been evaluated and could be potential future targets for policy changes or interventions, including: task shifting; additional non-financial resource inputs; information to patients; health worker training; and changes to organisational management within a GP practice.

\section{Limitations}

The limitations of this study include: the biased nature of the available evidence; diffuse nature of the interventions; the small number of studies overall; and the limited number of studies for different categories of interventions. Thus, the conclusions drawn here should be approached with caution.

\section{Conclusions}

The process of delivering the routine immunisation programme through GP Practices in England is well described, but contained across a wide range of documents. This has been synthesised into a clear logic model with underlying assumptions that will be valuable to policymakers and researchers to develop and test interventions in the context of declining national immunisation coverage. The evidence base for interventions to increase immunisation coverage in the England context are limited by a small number of studies for different categories of interventions; and by significant risks of bias in much of the evidence base. Several areas remain unexplored as targets for interventions, especially modifications to the organisational management of GP Practices.

\section{Additional file}

Additional file 1: Medline Search Strategy. (DOCX 15 kb)

\section{Abbreviations}

B\&A: Before and after study design; BMA: British Medical Association; CB\&A: Controlled before and after study design; CVD: Cardiovascular disease; CHIS: Child Health Information System; Cl: 95\% confidence interval; DH: Department of Health; GMS: General Medical Service contract; GP: General Practitioner; GPC: General Practitioners Committee;
HCA: Healthcare Assistant; HPV: Human papillomavirus; HSCA: Health and Social Care Act; HV: Health visitor; ITS: Interrupted time series study design; JCVI: Joint Committee on Vaccines and Immunisations; MHRA: Medicines and Healthcare Products Regulatory Agency; MMR: Measles, mumps and rubella vaccine; NHSD: National Health Service Digital; NHSEm: National Health Service Employers; NHSE: National Health Service England; OR: Odds ratio; PHE: Public Health England; PMS: Personal Medical Services contract; QOF: Quality and Outcomes Framework; RCT: Randomised controlled trial; VPD: Vaccine preventable disease; WHO: World Health Organisation

\section{Acknowledgements}

The authors would like to thank the advice and support provided by Dr Mary Ramsay and staff in the Vaccines Department at Public Health England.

\section{Funding}

The research was funded by the National Institute for Health Research Health Protection Research Unit (NIHR HPRU) in Immunisation at the London School of Hygiene and Tropical Medicine in partnership with Public Health England (PHE).

\section{Availability of data and materials}

The datasets used and analysed during the current study are available from the corresponding author on reasonable request

\section{Authors' contributions}

TCB conceived the study with advice from SMJ. TCB undertook the searches and screening by titles. TCB and SMJ reviewed the studies for inclusion and undertook quality scoring. TCB wrote the initial draft of the paper, with editorial advice from SMJ. Both authors read and approved the final manuscript.

Ethics approval and consent to participate

This study was approved by the LSHTM Ethics Committee. As it is a secondary analysis of publicly available data no consent was required.

\section{Consent for publication}

Not applicable

\section{Competing interests}

The authors declare that they have no competing interests.

\section{Publisher's Note}

Springer Nature remains neutral with regard to jurisdictional claims in published maps and institutional affiliations.

Received: 9 April 2018 Accepted: 19 November 2018

Published online: 06 December 2018

\section{References}

1. DH. Health and Social Care Act 2012: fact sheets. 2018. Available from: https://www.gov.uk/government/publications/health-and-social-care-act2012-fact-sheets. Accessed 28 Feb 2018

2. Chantler T, Lwembe S, Saliba V, Raj T, Mays N, Ramsay M, et al. "It's a complex mesh" - how large-scale health system reorganisation affected the delivery of the immunisation programme in England: a qualitative study. BMC Health Serv Res. 2016;3:1-14.

3. PHE. The routine immunisation schedule 2016-2017. 2017. Available from: https://www.gov.uk/government/publications/the-complete-routineimmunisation-schedule. Accessed 28 Feb 2018

4. NHS Digital. Childhood Vaccination Coverage Statistics 2016-2017. London: Pub. NHS Digital; 2017.

5. ECDC. Measles. 2018. Available from: https://ecdc.europa.eu/en/measles. Accessed 28 Feb 2018.

6. PHE. Measles outbreaks confirmed in 5 areas across UK. 2018. Available from: https://www.gov.uk/government/news/measles-outbreaks-confirmedin-leeds-liverpool-and-birmingham. Accessed 28 Feb 2018.

7. PHE. Shingles vaccine coverage report, England: September 2017 to January 2018. London: Pub. Public Health England; 2018.

8. Norbury M, Fawkes N, Guthrie B. Impact of the GP contract on inequalities associated with influenza immunisation: A retrospective populationdatabase analysis. Br. J. Gen. Pract. 2011;61:e379-85. 
9. Mixer RE, Jamrozik K, Newsom D. Ethnicity as a correlate of the uptake of the first dose of mumps, measles and rubella vaccine. J. Epidemiol. Community Health. 2007;61:797-801.

10. Pearce A, Law C, Elliman D, Cole TJ, Bedford H. Millennium Cohort Study Child Health Group. Factors associated with uptake of measles, mumps, and rubella vaccine (MMR) and use of single antigen vaccines in a contemporary UK cohort: prospective cohort study. BMJ. 2008;336:754-7.

11. Pebody RG, Hippisley-Cox J, Harcourt S, Pringle M, Painter M, Smith G. Uptake of pneumococcal polysaccharide vaccine in at-risk populations in England and Wales 1999-2005. Epidemiol. Infect. 2008;136:360-9.

12. NHS Digital. NHS Immunisation Statistics: England, 2015-16. Available from: https://digital.nhs.uk/data-and-information/publications/statistical/nhsimmunisation-statistics/nhs-immunisation-statistics-england-2015-16. Accessed 28 Feb 2018.

13. Coupland C, Harcourt S, Vinogradova Y, Smith G, Joseph C, Pringle M, et al. Inequalities in uptake of influenza vaccine by deprivation and risk group: Time trends analysis. Vaccine. 2007:25:7363-71.

14. Wagner KS, van Wijgerden JCJ, Andrews N, Goulden K, White JM. Childhood vaccination coverage by ethnicity within London between 2006/2007 and 2010/2011. Arch. Dis. Child. 2014;99:348-53.

15. Fisher H, Audrey S, Mytton JA, Hickman M, Trotter C. Examining inequalities in the uptake of the school-based HPV vaccination programme in England: a retrospective cohort study. J. Public Health. 2014;36:36-45.

16. Baker D, Garrow A, Shiels C. Inequalities in immunisation and breast feeding in an ethnically diverse urban area: cross-sectional study in Manchester, UK. J. Epidemiol. Community Health. 2011;65:346-52.

17. Friederichs V, Cameron JC, Robertson C. Impact of adverse publicity on MMR vaccine uptake: a population based analysis of vaccine uptake records for one million children, born 1987-2004. Arch. Dis. Child. 2006;91:465-8.

18. Hawker Il, Olowokure B, Wood AL, Wilson RC, Johnson R. Widening inequalities in MMR vaccine uptake rates among ethnic groups in an urban area of the UK during a period of vaccine controversy (1994-2000). Vaccine. 2007;25:7516-9.

19. Kumar VM, Whynes DK. Explaining variation in the uptake of HPV vaccination in England. BMC Public Health. 2011;11:172.

20. Frew PM, Lutz CS. Interventions to increase pediatric vaccine uptake: An overview of recent findings. Hum. Vaccin. Immunother. 2017;13:2503-11.

21. Das JK, Salam RA, Arshad A, Lassi ZS, Bhutta ZA. Systematic Review and Meta-Analysis of Interventions to Improve Access and Coverage of Adolescent Immunizations. J. Adolesc. Heal. 2016;59:540-8.

22. Thomas RE, Lorenzetti DL. Interventions to increase influenza vaccination rates of those 60 years and older in the community. Cochrane Database Syst. Rev. 2018:5:CD005188.

23. Aigbogun NW, Hawker Jl, Stewart A. Interventions to increase influenza vaccination rates in children with high-risk conditions - A systematic review. Vaccine. 2015;33:759-70.

24. Walton S, Bedford H. Immunization of looked-after children and young people: a review of the literature. Child. Care. Health Dev. 2017:43:463-80.

25. Jarrett C, Wilson R, O'Leary M, Eckersberger E, Larson HJ, Eskola J, et al. Strategies for addressing vaccine hesitancy - A systematic review. Vaccine. 2015;33:4180-90.

26. Jaca A, Mathebula L, Iweze A, Pienaar E, Wiysonge CS. A systematic review of strategies for reducing missed opportunities for vaccination. Vaccine. 2018;36:2921-7.

27. Crocker-Buque T, Edelstein M, Mounier-Jack S. Interventions to reduce inequalities in vaccine uptake in children and adolescents aged $<19$ years: a systematic review. J. Epidemiol. Community Health. 2017;71:87-97.

28. Jones Cooper SN, Walton-Moss B. Using Reminder/Recall Systems to Improve Influenza Immunization Rates in Children With Asthma. J. Pediatr. Heal. Care. 2013;27:327-33.

29. Jacobson Vann J, Jacobson R, Coyne-Beasley T, Asafu-Adjei J, Szzilagyi P. Patient reminder and recall interventions to improve immunization rates. Cochrane Database Syst. Rev. 2018;1:CD003941.

30. Gurol-Urganci I, de Jongh T, Vodopivec-Jamsek V, Atun R, Car J. Mobile phone messaging reminders for attendance at healthcare appointments. Cochrane Database Syst. Rev. 2013:CD007458. https://doi.org/10.1002/ 14651858.CD007458.pub3.

31. Saeterdal I, Lewin S, Austvoll-Dahlgren A, Glenton C, Munabi-Babigumira S Interventions aimed at communities to inform and/or educate about early childhood vaccination. Cochrane Database Syst. Rev. 2014:CD010232. https://doi.org/10.1002/14651858.CD010232.pub2.
32. Dumit EM, Novillo-Ortiz D, Contreras M, Velandia M, Danovaro-Holliday MC. The use of eHealth with immunizations: An overview of systematic reviews. Vaccine. 2018. https://doi.org/10.1016/j.vaccine.2018.06.076.

33. Williams N, Woodward H, Majeed A, Saxena S. Primary care strategies to improve childhood immunisation uptake in developed countries: systematic review. JRSM Short Rep. 2011;2:81.

34. Arditi $C$, Rège-Walther $M$, Durieux $P$, Burnand B. Computer-generated reminders delivered on paper to healthcare professionals: effects on professional practice and healthcare outcomes. Cochrane Database Syst. Rev. 2017;7:CD001175.

35. Scott A, Sivey P, Ait Ouakrim D, Willenberg L, Naccarella L, Furler J, et al. The effect of financial incentives on the quality of health care provided by primary care physicians. Cochrane database Syst. Rev. 2011:CD008451.

36. Adams J, Bateman B, Becker F, Cresswell T, Flynn D, McNaughton R, et al. Effectiveness and acceptability of parental financial incentives and quasimandatory schemes for increasing uptake of vaccinations in preschool children: Systematic review, qualitative study and discrete choice experiment. Health Technol Assess. 2015;19(94):1-176.

37. Bowen GA. Document Analysis as a Qualitative Research Method. Qual. Res. J. 2009;9:27-40.

38. Moore G, Audrey S, Barker M, Bond L. Process evaluation of complex interventions. London: Pub. MEdical Research Council; 2014.

39. Moher D, Liberati A, Tetzlaff J, Altman DG, PRISMA Group. Preferred reporting items for systematic reviews and meta-analyses: the PRISMA statement. BMJ. 2009;339:b2535.

40. JPT Higgins, S Green. Cochrane Handbook for Systematic Reviews of Interventions Version 5.1.0Pub. The Cochrane Collaboration; 2011. Available from: http://handbook-5-1.cochrane.org/. Accessed 17 Sept 2019

41. NHLBI. Study Quality Assessment Tools. 2018. Available from: https:/www.nhlbi. nih.gov/health-topics/study-quality-assessment-tools. Accessed 14 Feb 2018.

42. NHS England. NHS public health functions agreement 2017-18: Core service specification National immunisation programme. London: Pub. NHS England; 2017.

43. Edelstein M, Crocker-Buque T, Tsang C, Eugenio O, Hopson T, Pebody R, et al. Extracting general practice data for timely vaccine coverage estimates: The England experience. Vaccine. 2017;35:5110-4.

44. NHS England. Child Health Information Services (CHIS) Provider Service Specification. London: Pub. NHS England; 2015.

45. MHRA. Yellow Card Scheme. 2017. Available from: https://yellowcard.mhra. gov.uk/. Accessed 21 Feb 2018

46. PHE. Immunisation against infectious disease - The Green Book. Available from: https://www.gov.uk/government/collections/immunisation-againstinfectious-disease-the-green-book\#the-green-book. Accessed 13 Dec 2017

47. Government Equalities Office. Equality Act 2010: guidance. 2015. Available from: https:/www.gov.uk/guidance/equality-act-2010-guidance. Accessed 28 Feb 2018

48. Giuffrida A, Gosden T, Forland F, Kristiansen I, Sergison M, Leese B, et al. Target payments in primary care: effects on professional practice and health care outcomes. Cochrane Database Syst. Rev. 2000;4:CD000531.

49. Jacobson, Vann JC, Szilagyi P. Patient reminder and patient recall systems to improve immunization rates. Cochrane Database Syst. Rev. 2005:CD003941.

50. Thomas RE, Russell ML, Lorenzetti DL. Systematic review of interventions to increase influenza vaccination rates of those 60 years and older. Vaccine. 2010;28:1684-701.

51. Elkan R, Kendrick D, Hewitt M, Robinson JJA, Tolley K, Blair M, et al. The effectiveness of domiciliary health visiting: A systematic review of international studies and a selective review of the British literature. Health Technol. Assess. 2000;4:1-330.

52. Arthur AJ, Matthews RJ, Jagger C, Clarke M, Hipkin A, Bennison DP. Improving uptake of influenza vaccination among older people: a randomised controlled trial. Br. J. Gen. Pract. 2002;52:717-22.

53. Hull S, Hagdrup N, Hart B, Griffiths C, Hennessy E. Boosting uptake of influenza immunisation: A randomised controlled trial of telephone appointing in general practice. Br. J. Gen. Pract. 2002;52:712-6.

54. Nuttall $D$. The influence of health professionals on the uptake of the influenza immunization. Br. J. Community Nurs. 2003;8:391-6.

55. Herrett E, Williamson E, van Staa T, Ranopa M, Free C, Chadborn T, et al. Text messaging reminders for influenza vaccine in primary care: a cluster randomised controlled trial (TXT4FLUJAB). BMJ Open. 2016;6:e010069.

56. Siriwardena AN, Rashid A, Johnson MRD, Dewey ME. Cluster randomised controlled trial of an educational outreach visit to improve influenza and pneumococcal immunisation rates in primary care. Br. J. Gen. Pract. 2002:52: $735-40$. 
57. Siriwardena A, Rashid A, Johnson M, Hazelwood L, Wilburn T, ANS, et al. Improving influenza and pneumococcal vaccination uptake in high-risk groups in Lincolnshire: quality improvement report from a large rural county. Qual. Prim. Care. 2003:11:19-28.

58. Porter-Jones G, Williams S, Powell C, Pusey L, Roberts RJ. Impact of a novel way to communicate information about MMR on uptake of MMR vaccine: A randomized controlled trial. Public Health. 2009;123:78-80.

59. Shourie $\mathrm{S}$, Jackson $\mathrm{C}$, Cheater FM, Bekker HL, Edlin R, Tubeuf $\mathrm{S}$, et al. A cluster randomised controlled trial of a web based decision aid to support parents' decisions about their child's Measles Mumps and Rubella (MMR) vaccination. Vaccine. 2013:31:6003-10.

60. Le Menach A, Boxall N, Amirthalingam G, Maddock L, Balasegaram S, Mindlin M, et al. Increased measles-mumps-rubella (MMR) vaccine uptake in the context of a targeted immunisation campaign during a measles outbreak in a vaccine-reluctant community in England. Vaccine. 2014;32:1147-52.

61. Cockman P, Dawson L, Mathur R, Hull S. Improving MMR vaccination rates: herd immunity is a realistic goal. Br. Med. J. 2011;343:-d5703.

62. MacDonald P. Ensuring excellence in immunization services. Hum. Vaccin. Immunother. 2016;12:252-4.

63. Atchison C, Zvoc M, Balakrishnan R. The evaluation of a standardized call/ recall system for childhood immunizations in Wandsworth. England. J. Community Health. 2013:38:581-7.

64. Henderson R, Oates K, MacDonald H, Smith WCS, Selvaraj S. Factors influencing the uptake of childhood immunisation in rural areas. Br. J. Gen. Pract. 2004;54:114-8

65. Gosden T, Sibbald B, Williams J, Petchey R, Leese B. Paying doctors by salary: A controlled study of general practitioner behaviour in England. Health Policy. 2003;64:415-23.

66. McDonald P, Friedman EH, Banks A, Anderson R, Carman V. Pneumococcal vaccine campaign based in general practice. BMJ. 1997;314:1094-8.

67. Mantzari E, Vogt F, Marteau TM. Financial incentives for increasing uptake of HPV vaccinations: A randomized controlled trial. Heal. Psychol. 2015;34:160-71.

68. Kontopantelis E, Doran T, Gravelle H, Goudie R, Siciliani L, Sutton M, et al. Family doctor responses to changes in incentives for influenza immunization under the U.K. quality and outcomes framework pay-for-performance scheme. Health Serv. Res. 2012;47:1117-36.

69. Kontopantelis E, Springate D, Reeves D, Ashcroft DM, Valderas JM, Doran T. Withdrawing performance indicators: Retrospective analysis of general practice performance under UK Quality and Outcomes Framework. BMJ. 2014;348:9330

70. Gillam S, Steel N. The Quality and Outcomes Framework--where next? BMJ. 2013;346:f659

71. Dexter $L$, Teare MD, Dexter M, Siriwardena AN, Read RC. Strategies to increase influenza vaccination rates: Outcomes of a nationwide crosssectional survey of UK general practice. BMJ Open. 2012;2.

72. Lamden KH, Gemmell I. General practice factors and MMR vaccine uptake: structure, process and demography. J. Public Health. 2008;30:251-7.

73. Arthur A, Mattehws R, Jagger C. A home based health check combined with influenza vaccination improved uptake of influenza vaccination in people $>$ than or $=$ to 75 years of age. Br. J. Gen. Pract. 2002:52:717-22.

74. Tubeuf S, Edlin R, Shourie S, Cheater FM, Bekker H, Jackson C, et al. Cost effectiveness of a web-based decision aid for parents deciding about MMR vaccination: A three-arm cluster randomised controlled trial in primary care. Br J Gen Pract. 2014;64:e493-9.

\section{Ready to submit your research? Choose BMC and benefit from:}

- fast, convenient online submission

- thorough peer review by experienced researchers in your field

- rapid publication on acceptance

- support for research data, including large and complex data types

- gold Open Access which fosters wider collaboration and increased citations

- maximum visibility for your research: over $100 \mathrm{M}$ website views per year

At $\mathrm{BMC}$, research is always in progress.

Learn more biomedcentral.com/submissions 